\title{
PROSPEK SKENARIO KEBIJAKAN PENGELOLAAN LINGKUNGAN KAWASAN INDUSTRI (Studi Kasus Kawasan Industri Jababeka dan EJIP di Kabupaten Bekasi)
}

\author{
Temmy Wikaningrum \\ Program Studi Teknik Lingkungan \\ Fakultas Teknik Universitas Presiden \\ J1 Ki Hajar Dewantara, Jababeka Education Park, Cikarang, Jawa Barat 17550 \\ temmy@president.ac.id
}

\begin{abstract}
The key factors which supported to develop sustainaibility in the environmental management in the industrial estate was studied by many approaches. The principles of analysis were elaborated by the multi dimension key factors that affecting the policy of the environmental manager in ecology, economy, social, technology and estate management aspects. This study was initiated by considering and combining the dominant factors which the results of prior researches that using Multi-Dimensional Scaling (MDS) method. The dominants factors were reveiwed by expert judgment approach by Bourgeois matrix as the propective analysis tool. The analysis was focus in the key factors that has low value in the dependence (<1) but has high value in the influence $(>1)$ of the normalized graph of dependence-inluence. The key factors were a) implementation of $3 R$ for hazardous waste; b) industrial wastewater quality; c) industrial estate wastewater quality ;d) labor condition, and e) industrial water demand. The study was analyze that the optimistic scenario can be obtained by the industrial estate manager by conducting the strategic steps. The initial program was recommended by enforcing the industrial companies to improve their waste water quality and increasing $3 R$ of hazardous waste, that will enhance increasing the waste water quality of the centralized wastewater treatment of industrial estate. The environmental synergy between industrial company and industrial estate management will promote the good labour condition and stakeholders trust for more business opportunities that indicated by increasing industrial water demand.
\end{abstract}

Keywords: environmental management, industrial estate, prospective analysis, sustainable

Abstrak. Beberapa faktor-faktor penting yang mendukung keberlanjutan pengelolaan lingkungan kawasan industri telah dikaji dengan beberapa pendekatan. Prinsip kajian-kajian tersebut adalah dengan menganalisa faktor-faktor penting secara multi dimensi yang mempengaruhi kebijakan pengelola kawasan industri dalam aspek ekonomi, sosial, ekologi, teknologi dan pengelolaan. Penelitian ini diawali dengan merujuk dan menggabungkan faktor-faktor dominan dari penelitian-penelitian sebelumnya yang menggunakan metoda MDS. Faktor-faktor dominan tersebut dikaji propektifnya oleh beberapa pakar terpilih dengan pendekatan matrix Bourgeouis. Kajian ini selanjutnya difokuskan kepada faktor-faktor penentu yang memiliki nilai ketergantungan yang rendah $(<1)$, namun memiliki pengaruh yang tinggi $(>1)$ pada diagram pengaruh - ketergantungan yang telah dinormalsasi. Faktor penentu tersebut adalah a) 3R limbah B3; b) kualitas air limbah industri; c)kualitas air limbah kawasan industri; d) kondisi perburuhan; dan e) kebutuhan air industri. Dengan langkah-langkah staregis, pengelola kawasan industri dapat menerapkan skenario pengelolaan yang optimis. Rekomendasi langkah strategis dimulai dengan sinergi antara pengelola kawasan industri dan perusahaan industri dalam meningkatkan kualiats air limbah dan 3R limbah B3. Hal ini akan meningkatkan kondisi perburuhan yang kondusif dan meningkatkan kepercayaan pihak-pihak terkait yang akan meningkatkan peluang bisnis industri, dengan salah satu indikasinya berupa peningkatan kebutuhan air industri. Adanya peningkatan kebutuhan air industri akan mendorong aspek eknomi yang lebih baik kepada pengelola kawasan sehingga akan memberikan pelayanan yang lebih baik kepada perusahaan industri.

Kata Kunci: analisis prospektif, berkelanjutan, kawasan industri, multidimensional scaling, pengelolaan lingkungan

\section{PENDAHULUAN}

Pengelolaan lingkungan kawasan industri yang berkelanjutan sangat dibutuhkan bagi masyarakat Indonesia sejalan dengan pertumbuhan industri yang tinggi dan dampaknya yang luas, baik dampak ekologi, ekonomi maupun sosial, serta dibutuhkan dukungan teknologi yang tepat serta Sistem Manajemen Lingkungan yang kondusif. Analisis status keberlanjutan beberapa kawasan telah dilakukan oleh beberapa peneliti dalam 5 dimensi, yaitu 
dimensi ekonomi, ekologi, sosial, teknologi dan kelembagaan (pengelolaan). Hasil penelitian di Kawasan Industri Jababeka di kabupaten Bekasi (Wikaningrum 2015 dan Cahyanto 2016), menunjukkan bahwa pengelolaan lingkungan tergolong berkelanjutan untuk

dimensi kelembagaan, sedangkan dimensi sosial, ekonomi, teknologi dan ekologi belum berkelanjutan. Sedangkan penelitian di East Jakarta Industrial Estate Park di Kabupaten Bekasi (Budiyanto 2016) pada 5 dimensi tersebut menunjukkan keberlanjutan untuk seluruh dimensinya.

Tabel 1. Rekapitulasi faktor -faktor penting hasil analisis MDS dari data sekunder

\begin{tabular}{|c|c|c|c|c|c|c|}
\hline DIMENSI & & $1(*)$ & $2(* *)$ & $2(* * *)$ & Total & Prospektif \\
\hline \multirow[t]{5}{*}{ Ekologi } & 1 & 3R limbah B3 & $\begin{array}{l}\text { Kualitas air limbah } \\
\text { pelanggan }\end{array}$ & $\begin{array}{l}\text { Pemanfaatan } \\
\text { Lahan (BCR) }\end{array}$ & 11 & 9 \\
\hline & 2 & $\begin{array}{l}\text { Konservasi air \& penurunan } \\
\text { beban pencemaran air }\end{array}$ & Taman & $\begin{array}{l}\text { Kualitas Air } \\
\text { Limbah Tenant }\end{array}$ & & \\
\hline & 3 & Penurunan pencemaran udara & $\begin{array}{l}\text { Upaya pencegahan } \\
\text { pencemaran drainase }\end{array}$ & $\begin{array}{l}\text { Kualitas Air } \\
\text { Limbah Kawasan }\end{array}$ & & \\
\hline & 4 & & Kuantitas sumber air baku & & & \\
\hline & 5 & & $\begin{array}{l}\text { Kualitas distribusi air bersih } \\
\text { ke pelanggan }\end{array}$ & & & \\
\hline \multirow[t]{5}{*}{ Ekonomi } & 6 & Dana konservasi air & $\begin{array}{l}\text { Tarif pemeliharaan kawasan } \\
\text { (MC) }\end{array}$ & Air Baku air bersih & 13 & 13 \\
\hline & 7 & $\begin{array}{l}\text { Dana penurunan pencemaran } \\
\text { udara }\end{array}$ & Pameran Produk & $\begin{array}{l}\text { Sharing } \\
\text { keuntungan }\end{array}$ & & \\
\hline & 8 & Dana 3R Limbah B3 & Iklan & $\begin{array}{l}\text { Kebutuhan air } \\
\text { industri tenant }\end{array}$ & & \\
\hline & 9 & Dana Pengembangan masyarakat & Tarif Air Limbah & & & \\
\hline & 10 & Dana implementasi SML & Komersial Ruko & & & \\
\hline \multirow[t]{4}{*}{ Sosial } & 11 & $\begin{array}{l}\text { Monitoring dan evaluasi program } \\
\text { pengembangan masyarakat }\end{array}$ & Kemampuan komunikasi & $\begin{array}{l}\text { Kondisi } \\
\text { perburuhan }\end{array}$ & 9 & 9 \\
\hline & 12 & Hubungan sosial & $\begin{array}{l}\text { penertiban transportasi } \\
\text { umum }\end{array}$ & $\begin{array}{l}\text { Turnover } \\
\text { karyawan }\end{array}$ & & \\
\hline & 13 & & sarana kesehatan & $\begin{array}{l}\text { Penyerapan } \\
\text { Tenaga Kerja } \\
\text { Lokal }\end{array}$ & & \\
\hline & 14 & & Patroli keamanan & & & \\
\hline \multirow[t]{5}{*}{ Teknologi } & 15 & $\begin{array}{l}\text { Teknologi penurunan pencemaran } \\
\text { udara }\end{array}$ & Teknologi distribusi gas & ISO 14001 & 11 & 11 \\
\hline & 16 & Teknologi efisiensi energi & $\begin{array}{l}\text { Teknologi Peralatan } \\
\text { Laboratorium }\end{array}$ & $\begin{array}{l}\text { Pre treatment air } \\
\text { limbah pelanggan }\end{array}$ & & \\
\hline & 17 & Teknologi 3R limbah B3 & $\begin{array}{l}\text { Teknologi supplai sir bersih } \\
\text { dengan sistem perpompaan }\end{array}$ & ISO 9001 & & \\
\hline & 18 & & Teknologi fiber optic & & & \\
\hline & 19 & & $\begin{array}{l}\text { Teknologi LED (Light } \\
\text { Emited Dioda) }\end{array}$ & & & \\
\hline \multirow[t]{4}{*}{$\begin{array}{l}\text { Kelemba- } \\
\text { gaan }\end{array}$} & 20 & Bechmarking SML & Regulasi kawasan & $\begin{array}{l}\text { Monitoring UKL } \\
\text { \& UPL }\end{array}$ & 9 & 9 \\
\hline & & DRKPL untuk PROPER & $\begin{array}{l}\text { Kesesuaian persyaratan } \\
\text { manajemen mutu } \\
\text { lingkungan }\end{array}$ & Serikat Pekerja & & \\
\hline & 22 & & $\begin{array}{l}\text { inovasi pengembangan } \\
\text { produk }\end{array}$ & $\begin{array}{l}\text { Sosialisasi } \\
\text { Kawasan }\end{array}$ & & \\
\hline & 23 & & $\begin{array}{l}\text { Tindak lanjut keluhan } \\
\text { pelanggan }\end{array}$ & & & \\
\hline Total & & 15 & 23 & 15 & 53 & 51 \\
\hline
\end{tabular}

(*) Wikaningrum et. al. (2015); (**) Cahyanto et. al . (2016); (***)Budiyanto et. al .(2015)

Dalam penelitian ini dilakukan analisis lanjutan terhadap 53 faktor penting yang dihasilkan dari analisis MDS (multidimensional scaling) pada penelitian sebelumnya yang dirangkum dalam Tabel
1. Analisis prospektif terhadap 53 faktor penting tersebut dilakukan melaui in depth interview kepada expert terpilih dengan format kuesioner matrik Bourgeois. Tujuan dari penelitian ini adalah 
menentukan prospek alternatif-kebijakan strategis pengelolaan lingkungan kawasan industri agar berkelanjutan.

\section{METODOLOGI}

Seperti yang telah disebutkan sebelumnya, bahwa tujuan dari penelitian ini adalah menentukan prospek alternatif-kebijakan strategis pengelolaan lingkungan kawasan industri agar berkelanjutan. Untuk mencapai tujuan penelitian tersebut selanjutnya disusun kerangka pikir sebagai berikut :

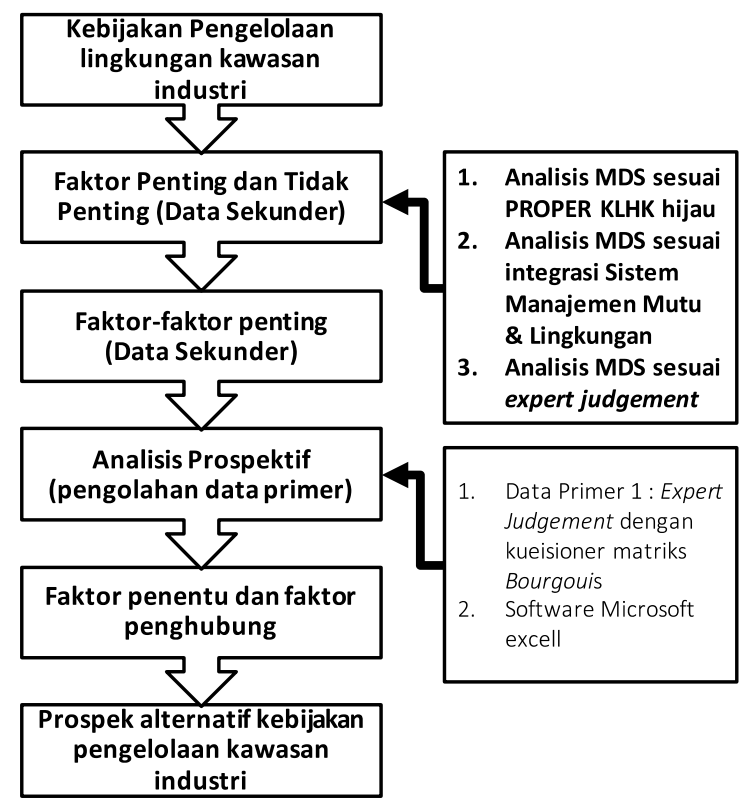

Gambar 1. Kerangka pikir penelitian

\section{Pemilihan Faktor Penting}

Penelitian ini menggunakan metode pendekatan sistem dengan studi kasus di kawasan industri di Cikarang Kabupaten Bekasi. Penentuan kebijakan strategis yang dibangun ditujukan untuk mendapatkan kebijakan pengelolaan lingkungan kawasan industri yang bersifat aplikatif, multi dimensi dan melibatkan beberapa pemangku kepentingan, serta merupakan kajian lintas sektor.

Penelitian dimulai dengan melakukan pengambilan data sekunder berupa faktorfaktor penting dan tidak penting dalam keberlanjutan pengelolaan dari penelitian sebelumnya berdasarkan pendekatan multidimensional scaling (MDS) dengan software rapfish (the rapid appraisal of fisheries status) yang selanjutnya dimodifikasi sesuai kebutuhan dalam penelitian tersebut. Pendekatan tersebut menggunakan kriteria PROPER KLHK peringkat hijau (Wikaningrum et.al 2015), menggunakan kriteria integrasi sistem manajemen mutu dan lingkungan (Cahyanto 2016), serta pendekatan expert judgement (Budiyanto 2016). Untuk faktor tidak penting selanjutnya tidak dikaji lebih lanjut karena bukan merupakan faktor dominan dalam system sesuai hasil analisis MDS tersebut.

Pada faktor-faktor penting hasil penelitian-penelitian sebelumnya hasil analisis MDS tersebut dilakukan analisis dengan metode prospektif untuk mengetahui faktor-faktor mana yang penting dalam kebijakan pengelolaan lingkungan kawasan industri. Pada analisis ini dilakukan pengambilan data primer melalui in depth interview dengan 8 orang para pakar yang representative dari berbagai pemangku kepentingan, seperti pemerintah, industri, dan tokoh masyarakat. Selanjutnya dari score hasil interview dengan kuesioner dengan matrik Bourgeois yang telah dinormalisasi dapat ditentukan penentu dan penghubung kebijakan pengelolaan lingkungan kawasan industri. Dari faktor-faktor penentu tersebut selanjutnta dibangun prospek alternatif kebijakan dengan skenario pesimis, moderat dan optimis.

\section{Penetapan Pakar dan Prosedur in depth interview}

Responden dalam penelitian ini terdiri para pakar yang dipilih secara sengaja (purposive sampling). Oleh karena teknik penetapan responden dengan cara menggali informasi dan pengetahuan (akuisisi pendapat) pakar, maka metoda ini termasuk metoda expert judgement. Tahapan analisis prospektif dengan pengisian form kuesioner, yaitu oleh 8 orang pakar yang terdiri dari tokoh masyarakat, perusahaan industri, BPLHD Jawa Barat, dan pengelola kawasan 
industri yang telah berpengalaman di bidangnya minimal selama 15 tahun.

Beberapa pertimbangan dalam pemilihan pakar untuk dijadikan sebagi responden adalah memenuhi kriteria sebagai berikut :

1. Mempunyai kompentensi dan pengalaman di bidang yang dikaji.

2. Keberadaan, keterjangkauan dan kesediaan untuk diwawancara.

3. Memiliki reputasi, kedudukan/jabatan dan telah menunjukkan kredibiltasnya sebagai pakar pada bidang yang diteliti.

4. Bersifat obyektif dan bersedia menerima pendapat responden lain.

\section{Metode Analisis Prospektif}

Dalam tahap ini dilakukan analisis prospektif terhadap faktor penting hasil dari analisis MDS dari penelitian sebelumnya. Kegiatan yang dilakukan adalah wawancara (indepth interview) kepada para pakar yang mewakili dari berbagai pemangku kepentingan yang telah berpengalaman di bidang pengelolaan lingkungan kawasan industri.

Software yang digunakan adalah Microsoft Excell yang dimodifikasi dengan penghitungan analisis prospektif. Analisis prospektif digunakan untuk mempersiapkan tindakan strategik yang perlu perlu dilakukan dan melihat apakah perubahan diperlukan di masa depan (Hardjomidjojo 2004). Tahapan analisis prospektif menurut Bourgeois dan Jesus (2004) adalah:

1. Menentukan tujuan penelitian yang dikaji secara spesifik dan dapat dimengerti oleh semua pakar yang akan diminta pendapatnya.

2. Identifikasi faktor-faktor yang berpengaruh dalam pencapaian tujuan tersebut biasanya merupakan kebutuhan stakeholders sistem yang dikaji.

3. Penilaian pengaruh langsung antar faktor. Semua faktor yang teridentifikasi dan terdefinisi akan dinilai pengaruh langsung antar faktor, berpedoman pada penilaian seperti tercantum dalam Tabel 2.
4. Penyusunan keadaan yang mungkin terjadi (state) pada faktor-faktor penting yang berpengaruh. Keadaan bukan merupakan tingkatan atau ukuran suatu faktor (seperti besar, sedang, kecil, atau baik/buruk), tetapi merupakan deskripsi tentang situasi dari sebuah faktor.

Tabel 2. Pedoman penilaian analisis prospektif

\begin{tabular}{cl}
\hline SKOR & \multicolumn{1}{c}{ PENGARUH } \\
\hline 0 & Tidak ada pengaruh \\
1 & Berpengaruh kecil \\
2 & Berpengaruh sedang \\
3 & Berpengaruh sangat kuat \\
\hline
\end{tabular}

Sumber : Godet (1999)

Menurut Godet (1999) pengaruh antar faktor diberikan skor oleh pakar terpilih dengan menggunakan pedoman analisis prospektif sesuai Tabel 2 dengan tahapan sebagai berikut :

1. Mengidentifikasi faktor-faktor yang berpotensi menjadi faktor kunci. Pada format Tabel 3 dinyatakan dalam A, B, $\mathrm{C}$ dan seterusnya. Faktor ini dalam penelitian diperoleh dari hasil analisis leverage / pengungkit analisis MDS.

2. Dilihat dahulu apakah faktor tersebut tidak ada pengaruhnya terhadap faktor lain, jika benar tidak ada pengaruh maka diberi nilai 0 .

3. Jika ada pengaruh, selanjutnya dilihat apakah pengaruhnya sangat kuat, jika ya diberi nilai 3 .

4. Jika ada pengaruh, baru dilihat apakah pengaruhnya kecil $=1$, atau berpengaruh sedang $=2$.

Tabel 3. Matriks pengaruh langsung antar faktor

\begin{tabular}{|c|c|c|c|c|c|}
\hline & $\mathrm{A}$ & $\mathrm{B}$ & $\mathrm{C}$ & $\mathrm{D}$ & $\mathrm{E}$ \\
\hline $\mathrm{A}$ & & & & & \\
\hline $\mathrm{B}$ & & & & & \\
\hline $\mathrm{C}$ & & & & & \\
\hline $\mathrm{D}$ & & & & & \\
\hline E & & & & & \\
\hline
\end{tabular}

Menurut Bourgeios dan Jesus (2004), hasil analisis faktor-faktor kunci sesuai Gambar 
2 memiliki arti sesuai dengan keberadaan pada kuadran dimana faktor kunci tersebut berada, yaitu :

1) Kuadran I (INPUT), memuat faktorfaktor yang mempunyai pengaruh kuat dengan tingkat ketergantungan yang kurang kuat. Faktor ini sebagai faktor penggerak (driving variables) yang berpengaruh paling kuat dalam sistem.

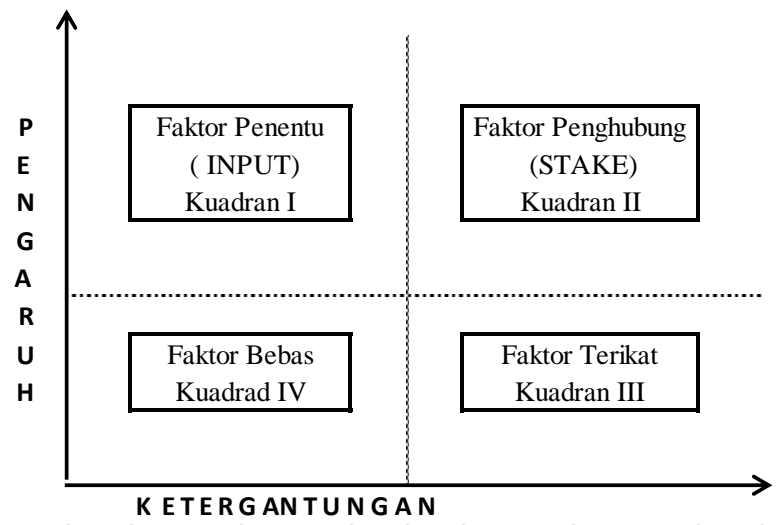

Gambar 2. Diagram pengaruh dan ketergantungan Bourgeios dan Jesus (2004)

2) Kuadran II (STAKES), memuat faktorfaktor yang mempunyai pengaruh dan ketergantungan yang kuat (leverage variables). Faktor pada kuadran ini merupakan peubah yang kuat.

3) Kuadran III (OUTPUT), memuat faktor-faktor yang mempunyai pengaruh kecil, namun tingkat ketergantungannya tinggi.

4) Kuadran IV (UNUSED), memuat faktor-faktor yang mempunyai pengaruh dan ketergantungan yang rendah.

\section{Lokasi dan Waktu Penelitian}

Penelitian dilakukan pada wilayah Kawasan Industri Jababeka (KIJA) dan East Jakarta Industrial Estate Park (EJIP) keduanya terletak Kabupaten Bekasi. Penelitian dilakukan pada bulan Juli 2017 - Desember 2017.

\section{HASIL DAN PEMBAHASAN}

Dari hasil analisis prospektif pada nilai yang telah dinormalisasi untuk dimensi ekologi diperoleh data hasil pemetaan pada Gambar 3, yang menunjukkan bahwa ada 3 faktor penentu sebagai driving force di kuadran 1 yaitu faktor a) Implementasi 3R limbah B3, b) kualitas air limbah dari industri, dan c) kualitas air limbah dari kawasan. Adapun faktor penghubung sebagai leverage variables (kuadran 2) terdiri dari a) Taman (penghijauan) dan b) pencegahan pencemaran drainase.

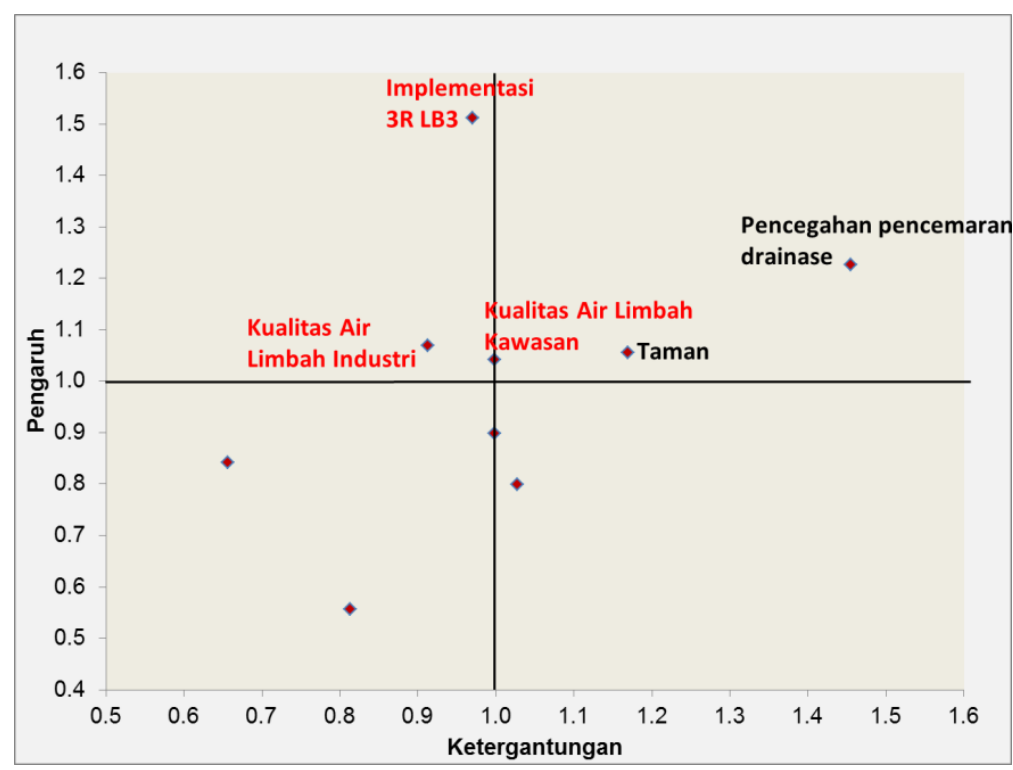

Gambar 3. Pemetaan faktor-faktor penting dimensi ekologi 
Hasil analisis ini menunjukkan bahwa faktor pencemaran lingkungan air limbah dan limbah B3 menjadi perhatian utama dibandingkan pencemaran udara maupun penghijauan. Hal ini karena pada kawasan industri yang diteliti telah melakukan penghijauan yang baik, dan jenis industri berlokasi di dalam kawasan tersebut secara umum tidak menghasilkan limbah gas namun menghaslkan air limbah dan limbah B3. Hal ini sejalan dengan penelitian sebelumnya (Dynasti et.al. 2017), bahwa strategi pengembangan dan pengelolaan kawasan industri menunjukkan strategi yang paling penting oleh responden adalah dengan "menghijaukan industri yang sudah ada". Dalam hal dimensi ekologi menjadi faktor yang strategis. Hasil perhitungan analisis prospektif untuk dimensi ekonomi dapat dilihat dalam Gambar 4 yang menunjukkan hanya 1 faktor yang menjadi penentu yaitu faktor kebutuhan industri, terdapat 6 faktor penghubung di kuadran 2 yaitu : a) alokasi Dana konservasi air; b) alokasi Dana implementasi Sistem Manajemen Lingkungan; c) Tarif maintenance charge kawasan; d) Tarif Air Bersih Kawasan; e) pameran produk; dan f) tersedianya air baku untuk air bersih. Dari hasil di atas menunjukkan bahwa jumlah kebutuhan air bersih menjadi faktor penggerak utama bagi dimensi ekonomi karena sebagai indikasi bahwa kondisi ekonomi dan bisnis industri dalam kawasan berjalan baik yang pada akhirnya akan mempengaruhi kondisi ekonomi pengelola kawasan industri.

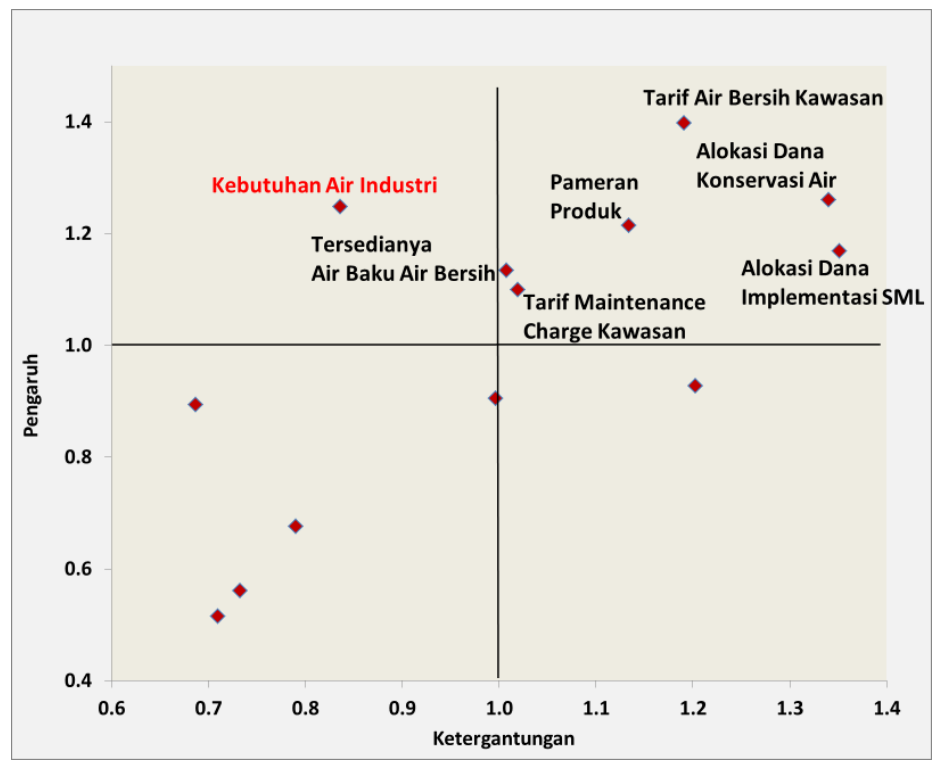

Gambar 4. Pemetaan faktor-faktor penting dimensi ekonomi

Penelitian di Rumania (Nastase et.al. 2010) terkait pengembangan kawasan industri yang berkelanjutan diperoleh hasil bahwa peran pemerintah dalam mendorong keberlanjutan pengelolaan kawasan industri terutama diperlukan yang terkait dari sektor ekonomi. Adapun program opsi strategisnya adalah environmental benchmarking, environmental leadership dan pro-active environmental strategies. Hal ini sejalan dengan pengembangan kawasan industri di Russia (Sosnovskikh 2017), bahwa peran penting pemerintah terutama dalam dimensi ekonomi sangat diperlukan dalam mendukung Industri Kecil dan Menengah. Hasil analisis prospektif untuk dimensi sosial, menunjukkan bahwa hanya ada 1 faktor penentu sesuai Gambar 5, yaitu kondisi perburuhan. Sedangkan 4 faktor penghubung sesuai kuadran 2 adalah : a) Monitoring dan evaluasi program 
pengembangan masyarakat oleh pengelola kawasan; b) Hubungan sosial Pengelola Kawasan secara internal \& eksternal; c) Turnover karyawan di industri; dan d) Penyerapan Tenaga Kerja Lokal. Hasil analisis ini menunjukkan bahwa potensi yang mempengaruhi ketidak berlanjutan dimensi sosial lebih ditentukan oleh kondisi para pekerja di masing-masing industri dibandingkan faktor masyarakat lokal, komunikasi sosial, maupun faktor keamanan. Hal ini disebabkan kondisi keamanan dan komunikasi di kawasan indutri yang diteliti sudah baik, serta area untuk masyarakat lokal juga semakin sedikit sehingga perannya tidak terlalu banyak lagi. Sedangkan kegiatan perburuhan sudah menjadi aktivitas yang bersifat nasional lintas perusahaan dan wilayah, sehingga pengaruhnya harus benar-benar diantisipasi.

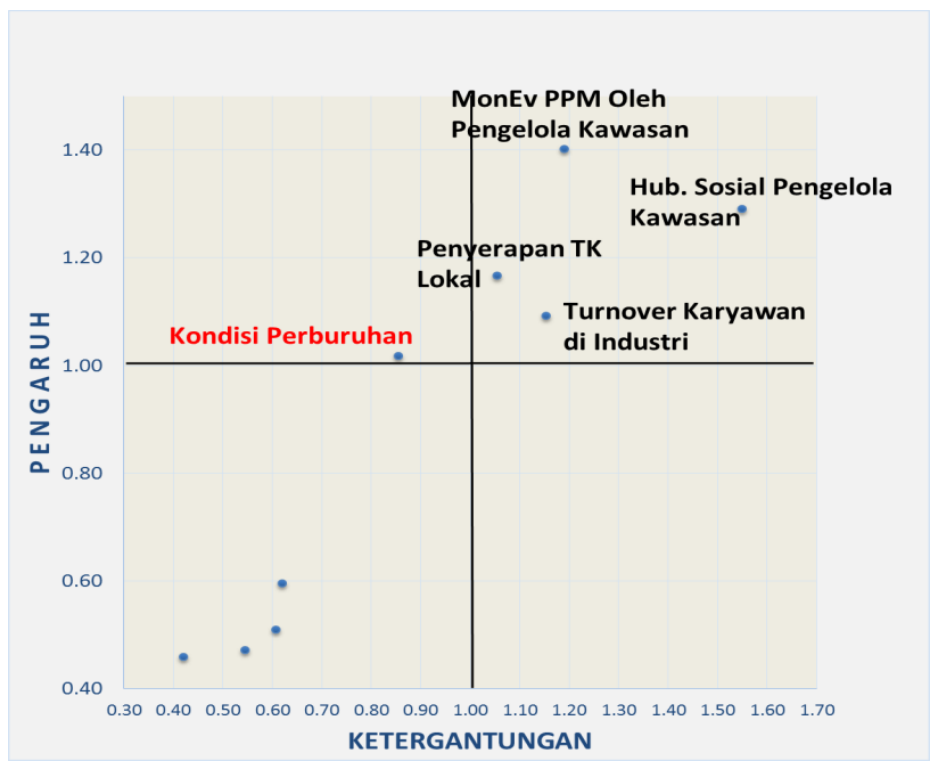

Gambar 5. Pemetaan faktor-faktor penting dimensi sosial

Hasil analisis dimensi teknologi sesuai dengan hasil pemetaan pada Gambar 6 menunjukkan bahwa tidak ada faktor yang menjadi faktor penentu, sedangkan faktor penghubung ada 4 yaitu a) Teknologi efisiensi energi ; b) Teknologi 3R Limbah B3; c)ISO 14001; dan d)ISO 9001. Tidak adanya faktor penentu menunjukkan telah didapatkannya akses teknologi yang memadai pada kawasan industri yang diteliti, yang menunjukkan fenomena global dengan kemudahan akses informasi. Sedangkan efidiensi energy merupakan isu yang diperhatikan terkait pelung penghematan biaya energi, juga peningkatan citra perusahaan. Adapun ISO 9001 mengenai system jaminan mutu dan ISO 14001 mengenai pengelolaan lingkungan menjadi perhatian karena selain meningkatkan kepercayaan pelanggan industri, juga sebagi sistem manajemen pengendalian kualitas dan pengelolaan ligkunngan yang diperlukan oleh perusahaan industri.

Hasil analisis dimensi kelembagaan sesuai pemetaan nilai pada Gambar 7 menunjukkan bahwa tidak terdapat faktor penentu , dan terdapat 4 faktor penghubung yaitu : a) Benchmarking Sistem Manajemen Mutu Lingkungan; b) DRKPL Proper Kawasa; c)Tata Tertib Kawasan; dan d) Kesesuaian persyaratan manajemen mutu lingkungan. Hasil analisis prospektif ini menunjukkan bahwa pada kawasan industri yang diteliti telah dilakukan pengelolaan yang baik oleh Pengelola Kawasan Industri, namun dengan terdapat faktor-faktor lain sebagai pengungkit yang harusdiperhatikan yaitu yang terkait dengan benchmarking, 
Proper KLHK, Tata Tertib Kawasan, dan manajemen mutu lingkungan.

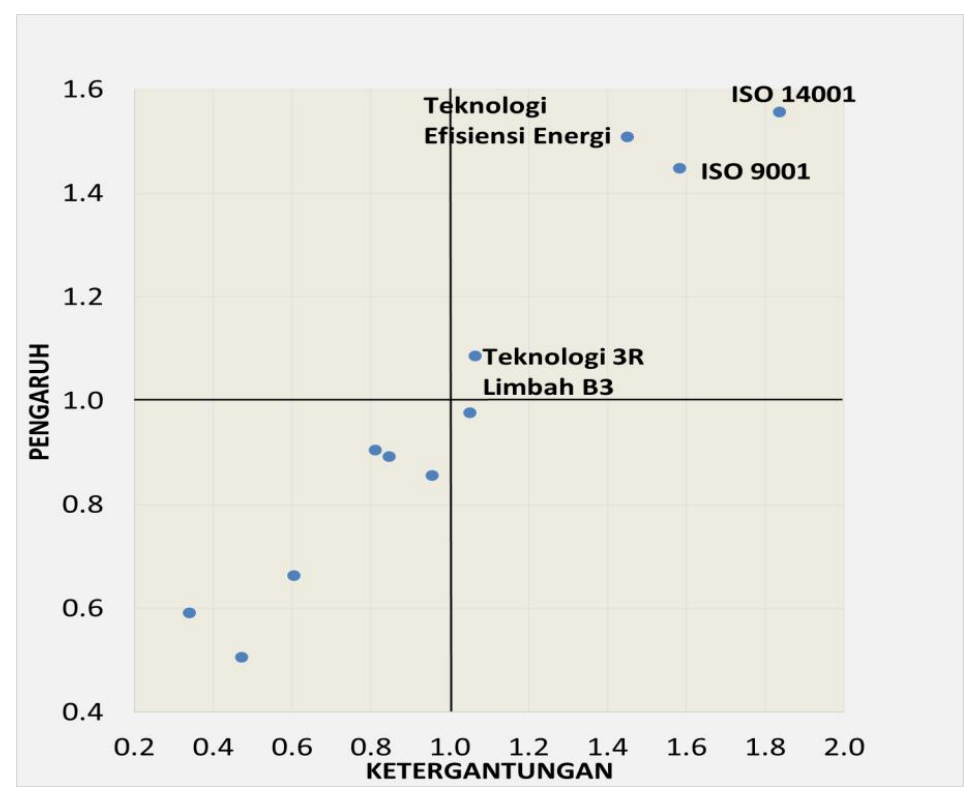

Gambar 6 Pemetaan faktor-faktor penting dimensi teknologi

Hasil analisis prospektif secara keseluruhan untuk 5 dimensi dirangkum dalam Tabel 4. Dengan demikian terdapat 5 faktor yang berasal 3 dimensi yaitu ekologi, ekonomi dan sosial yang menjadi penentu / driving force dalam sistem pengelolaan lingkungan kawasan industri agar berkelanjutan. Sedangkan dimensi teknologi dan kelembagaan tidak terdapat faktor penentu, meskipun terdapat banyak faktor penghubung sebagai faktor pengungkit / leverage factor sistem.

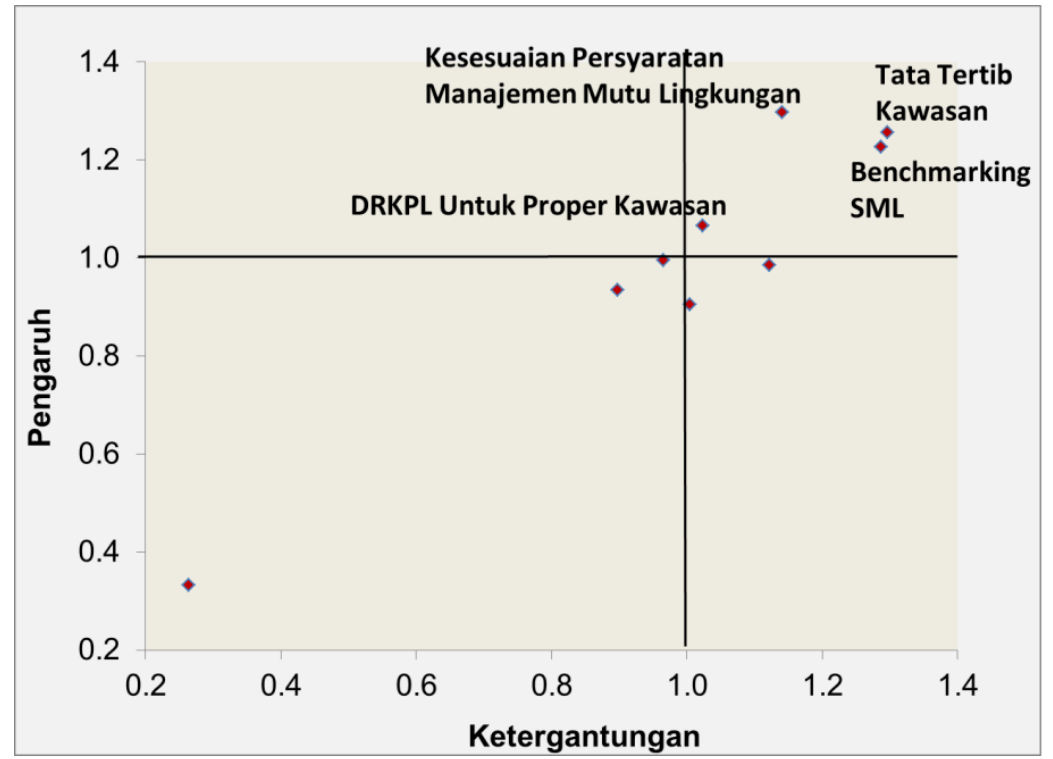

Gambar 7. Pemetaan faktor-faktor penting dimensi kelembagaan 
Tabel 4. Rangkuman hasil pemetaan analisis prospektif

\begin{tabular}{llll}
\hline \multicolumn{1}{c}{ Dimensi } & & \multicolumn{1}{c}{ Faktor Penghubung (Kuadran 2) } & Faktor Penentu (kuadran 1) \\
\hline EKOLOGI & 1 & Pencegahan Pencemaran Drainase & $\begin{array}{l}\text { Implementasi 3R Limbah B3 } \\
\text { Kualitas air limbah industri } \\
\text { Kualitas air limbah kawasan }\end{array}$ \\
\hline EKONOMI & 2 & Taman & Kebutuhan air oleh industri \\
& 4 & Alokasi dana konservasi air & \\
& 5 & Alokasi dana implementasi SML & \\
& 6 & Tarif maintenance kawasan & \\
& 7 & Tarif air bersih kawasan & \\
& 8 & Pameran Produk & \\
& 9 & Ketersediaan air baku & \\
\hline KELEMBAGAAN & 10 & Benchmarking SML & \\
& 11 & Tatib kawasan & \\
& 12 & Penertiban pelanggaran air limbah kawasan & \\
& 13 & Monev Program Pengembangan Masyarakat & \\
& 14 & Hubungan sosial & \\
& 15 & Turnover karyawan di Industri & \\
\hline TEKNOLOGI & 16 & Penyerapan tenaga kerja lokal & Teknologi efisiensi energi \\
\hline
\end{tabular}

Formulasi Kebijakan Pengelolaan Lingkungan Kawasan Industri

Skenario pengelolaan lingkungan kawasan industri disusun berdasarkan faktor-faktor penentu yang berpengaruh kuat namun dengan nilai keterganungan yang rendah sebagai driving force pada pengelolaan lingkungan kawasan industri. Dari faktor- faktor penentu tersebut dideskripsikan berbagai keadaan (state) yang mungkin akan terjadi di masa mendatang. Dari 4 faktor penentu (variabel) yang berpengaruh kuat terhadap pengelolaan lingkungan kawasan industri, selanjutnya dipilih keadaan yang mungkin terjadi di masa mendatang (Tabel $5)$.

Tabel 5. Kondisi (state) yang mungkin terjadi di waktu mendatang pada masing-masing faktor kunci

\begin{tabular}{llcccc}
\hline Dimensi & Faktor-faktor penentu & Kode variabel & A & B & C \\
\hline \multirow{2}{*}{ Ekologi } & Kualitas air limbah industri & 1 & meningkat & tetap & menurun \\
& Kualitas air limbah kawasan & 2 & meningkat & tetap & menurun \\
& Implementasi 3R Limbah B3 & 3 & meningkat & tetap & menurun \\
Sosial & Kondisi perburuhan & 4 & meningkat & tetap & menurun \\
\hline Ekonomi & Kebutuhan air oleh industri & 5 & meningkat & tetap & menurun \\
\hline
\end{tabular}

Pada Tabel 5 ditunjukkan bahwa setiap faktor penentu terdapat masing-masing tiga kemungkinan kinerjanya yang dapat terjadi di masa mendatang, yaitu tetap, meningkat, atau menurun. Setiap faktor penentu diberikan kode nomor 1 sampai dengan nomor 5, sedangkan keadaan yang mungkin terjadi diberikan kode $\mathrm{A}$ (meningkat), B (tetap), dan C (menurun). Selanjutnya dari berbagai kemungkinan sesuai Tabel 5 tersebut, selanjutnya disusun Tabel 6 yang merupakan kombinasi kondisi faktor-faktor penentu yang tidak mungkin terjadi secara bersamaan apabila sistem pengelolaan dilaksanakan dengan baik. Kombinasi antar kondisi faktor kunci (variabel) yang tidak mungkin tersebut selanjutnya dibuang (dieliminasi) dalam penyusunan skenario lebih lanjut. Sesuai kombinasi antar faktor dalam Tabel 6 terdapat 14 kombinasi keadaan yang tidak mungkin terjadi pada saat yang bersamaan. Misalnya untuk faktor penentu 1 
Tabel 6. Kombinasi kondisi (state) antar faktor yang tidak mungkin terjadi pada saat bersamaan

\begin{tabular}{cc}
\hline No & $\begin{array}{c}\text { Kombinasi variabel yang tidak mungkin } \\
\text { terjadi }\end{array}$ \\
\hline 1 & $1 \mathrm{~A}-3 \mathrm{C}$ \\
2 & $1 \mathrm{~A}-4 \mathrm{C}$ \\
3 & $1 \mathrm{~A}-5 \mathrm{C}$ \\
4 & $2 \mathrm{~A}-1 \mathrm{C}$ \\
5 & $2 \mathrm{~A}-1 \mathrm{~B}$ \\
6 & $2 \mathrm{~A}-3 \mathrm{C}$ \\
7 & $2 \mathrm{~A}-4 \mathrm{C}$ \\
8 & $2 \mathrm{~A}-5 \mathrm{C}$ \\
9 & $3 \mathrm{~A}-4 \mathrm{C}$ \\
10 & $3 \mathrm{~A}-5 \mathrm{C}$ \\
11 & $4 \mathrm{~A}-5 \mathrm{C}$ \\
12 & $5 \mathrm{~A}-1 \mathrm{C}$ \\
13 & $5 \mathrm{~A}-2 \mathrm{C}$ \\
14 & $5 \mathrm{~A}-4 \mathrm{C}$ \\
\hline
\end{tabular}

(kualitas air limbah industri), tidak mungkin kualitas air limbah terjadi peningkatan (menjadi lebih baik) pada kondisi 1A apabila faktor penentu implementasi 3R limbah B3 (kondisi 3C) menurun, karena keberhasilan pengelolaan limbah B3 berpengaruh di industri pada keberhasilan pre-treatment air limbah industri. Demikian juga kondisi 1A yaitu kualitas air limbah industri meningkat lebih baik tidak mungkin terjadi apabila kondisi buruh menurun (kondisi 4C), karena buruh (pekerja) yang melakukan pekerjaan langsung dalam pengelolaan air limbah di industri.

Tabel 7. Pemetaan keadaan faktor-faktor penentu pengelolaan lingkungan kawasan industry

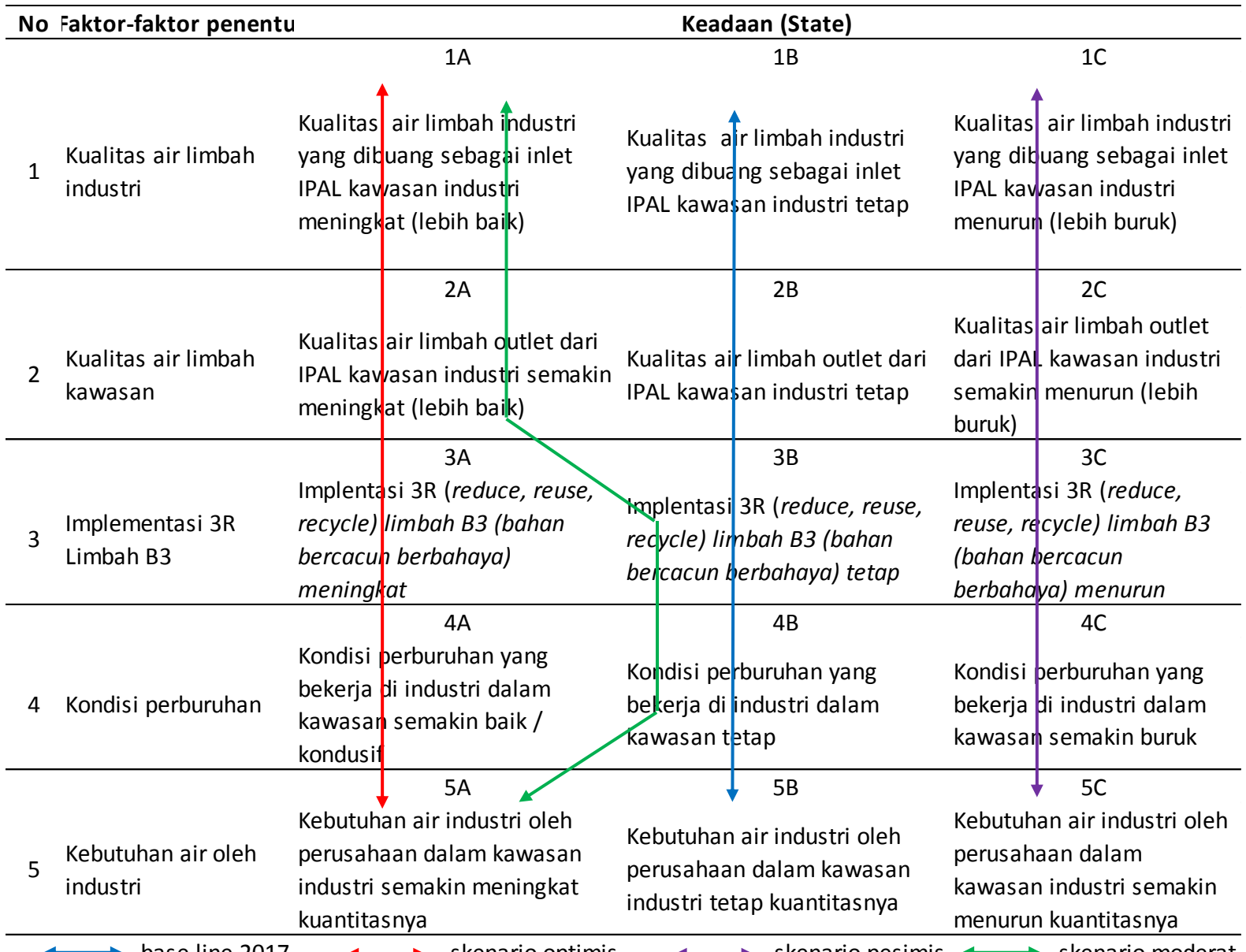


Menurut Hardjomidjojo (2002), penyusunan skenario dimaksudkan untuk memprediksi kemungkinan yang dapat terjadi pada faktor tersebut, yaitu apakah akan berkembang ke arah yang lebih baik dari sekarang, tetap, atau akan semakin buruk dari keadaan sekarang.Pemetaan faktor penentu dan kemungkinan keadaan yang mungkin terjadi dirangkum pada Tabel 7.

Berdasarkan hasil pemetaan pada Tabel 7, disusun skenario kebijakan pengelolaan lingkungan kawasan industri. Kondisi sekarang sesuai data tahun 2017 (base line) merupakan kondisi awal untuk penentuan berbagai skenario. Sebenarnya banyak kemungkinan skenario kebijakan yang dapat disusun, namun pada penelitian ini dibatasi hanya tiga skenario yang dikembangkan yaitu skenario pesimis, moderat, dan optimis. Skenario pesimis merupakan keadaan yang mungkin terjadi apabila ada penurunan kualitas air limbah industri yang masuk ke IPAL terpadu (Instalasi Pengolahan Air Limbah) Kawasan sehingga menyebabkan kualitas air limbah yang dibuang ke badan air oleh pengelola kawasan juga menurun.

Turunnya kualitas air limbah industri dan kawasan dapat berdampak pada turunnya citra perusahaan industri yang pada akhirnya kepercayaan pelanggan dan order yang diterima industri juga menurun. Hal ini berarti kondisi ekonomi dan bisnis menurun yang akan berdampak pada penurunan kebutuhan air industri yang mengindikasikan penurunan kondisi ekonomi dan bisnis industri. Apabila kondisi ekonomi perusahaan industri menurun, dapat berdampak pada pengurangan kesejahteraan buruh dan bahkan pengurangan buruh sehingga kondisi perburuhan menurun. Apabila kondisi ekonomi dan perburuhan menurun akan berdampak pada penurunan implementasi 3R limbah B3, mengingat implementasi tersebut diperlukan dukungan kemampuan finansial dan komitmen dan loyalitas. Skenario optimis akan berlangsung kemungkinan sebaliknya dari uraian skenario pesimis di atas.

Skenario moderat dapat terjadi dengan peningkatan kualitas air limbah industri sehingga berdampak pada peningkatan kualitas air limbah kawasan menjadi lebih baik juga. Dengan kondisi ini, citra dan kepercayaan pelanggan meningkat sehingga omset dan order industri meningkat sehingga terjadi peningkatan kondisi ekonomi dengan indikasi penigkatan kebutuhan air industri. Dalam skenario ini, peningkatan kondisi ekonomi pada industri ini, belum dilakukan peningkatan pada implementasi 3R limbah B3 maupun peningkatan kesejahteraan buruh. Hal ini dapat terjadi apabila kepedulian lingkungan dan kepekaan sosial terhadap buruh pengusaha perusahaan masih terbatas pada yang bersifat mandatory. Peran pemerintah dalam mendorong keberlanjutan pengelolaan kawasan industri terutama diperlukan yang terkait dari sektor ekonomi (Nastase 2010)

\section{REKOMENDASI DAN KESIMPULAN}

Dari hasil penelitian dan pembahasan di atas, rekomendasi atas skenario optimis adalah yang paling tepat dilaksanakan. Yaitu dengan langkah strategis yang diawali oleh perbaikan kualitas air limbah pada masing-masing perusahaan industri yang menjadi pelanggan pengelola kawasan industri. Dalam hal ini diperlukan sinergi yang baik antara pengelola kawasan dan masing-masing perusahaan industri. Peningkatan kualitas air limbah industri akan berdampak positif dengan makin baiknya kualitas air limbah kawasan, yang akan meningkatkan kepercayaan pelanggan, pemerintah, dan perbankan dalam mendukung kondisi ekonomi dan bisnis industri maupun pengelola kawasan. Hal ini pada akhirnya 
akan meningkatkan kondisi ekonomi perusahaan industri dan perusahaan pengelola kawasan. Agar pengelolaan lingkungan berkelajutan, maka sejalan dengan peningkatan dimensi ekonomi, hendaknya jangan dilupakan untuk peningkatan dimensi sosial, yaitu peningkatan kesejahteraan buruh, dan peningkatan dimensi ekologi dan lingkungan, yaitu peningkatan implementasi 3R limbah B3. Implementasi 3R limbah B3 berperan penting dalam mendorong terbangunnya keberlanjutan pengelolaan lingkungan Eco-Industrial Park (Park et.al, 2016)

\section{UCAPAN TERIMA KASIH}

Kami menyampaikan penghargaan dan terimakasih yang sebesar-besarnya atas bantuan para pakar yang mendukung dalam penelitian ini, yaitu Bp Dwi Restiyanto (General Manager PT BITA), Bp Pien Budiyanto (Direktur PT Delta Enviro Indonesia), Ibu Nita Walla (BPLHD Jabar), Ibu Istingani, Bp Rachmat Yulianto Bp Aris D.C (ketiganya Senior Manager PT Jababeka Infrastruktur), Bp Didik Purbadi (General Manager PT KIJA), dan Bp Sumartono (Senior Manager PT CDP).

\section{DAFTAR PUSTAKA}

Bourgeois R., Jesus F. 2004. Participatory Prospective Analysis : Exploring and Anticipating Challenges with Stakeholders. CAPSA Monograph No. 46. United Nation

Budiyanto P, Saefuddin A, Putri EIK. 2015. Analisis Keberlanjutan PT East Jakarta Industrial Park dalam Mewujudkan Kawasan Industri yang berwawasan Lingkungan. Jurnal Pengeloaan Sumberdaya alam dan Lingkungan. Vol 5. no.2. IPB. Bogor

Cahyanto AD, Noorachmat BP, Noor E. 2016. Model Pengembangan Kebijakan Integrasi Sistem Manajemen Mutu dan Lingkungan. Jurnal Pengeloaan Sumberdaya alam dan Lingkungan. Vol 6. no. 1 IPB. Bogor

Godet M. 1999. Scenarios and Strategies, A Toolbox for Scenario Planning. Paris (FR) : Librairie des Arts es Meiters
Hardjomidjojo H. 2002. Metode Analisis Prospektif. Departemen Teknologi Industri Pertanian Fakultas Pertanian Institut Pertanian Bogor.IPB Press. Bogor

Jasper Beekmans, Erwin van der Krabben, Karel Martens, (2012) "An indicator for decline of industrial estates", Journal of European Real Estate Research, Vol. 5 Issue: 3, pp.229249, https://doi.org/10.1108/175392612112 82073

Kuznetsova Z, E. Farel R. 2016. A methodological framework for Eco Industrial Park design and optimization. Journal of Cleaner Production 126 308- 324

Park, JM, Park JY, Park HS. 2015. A review of the National Eco-Industrial Park Development Program in Korea: progress and achievements in the first phase, 2005-2010. Journal of Cleaner Production 114 (2016) 33-44

Saaty TL. 2008. Decision Making with The Analytical Hierarchy Process. Int. J. Services Sciences. Vol. 1. No. 1

Singal S. and Kapur A . 2002. Industrial estate planning and management in India-an integrated approach towards industrial ecology, Journal of Environmental Management, Vol 66, issue 1, September 2002, Pages 19-29

Sulaiman F.,Saefudin A., and Zain AFM. 2008. Strategi Pengelolaan Kawasan Industri Cilegon Menuju Eco Industrial Park, Journal of Regional and City Planning, Vol 19 No.2

Wikaningrum T, Noorachmat BP, Noor E. 2015. Kebijakan Pengelolaan Lingkungan Kawasan Industri sesuai Proper KLHK Peringkat Hijau. Jurnal Pengeloaan Sumberdaya alam dan Lingkungan. Vol 5. no.2. IPB. Bogor 